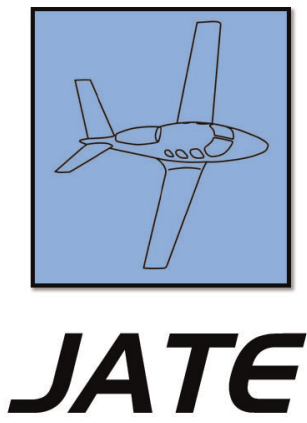

Journal of Aviation Technology and Engineering 8:2 (2019) 24-39

\title{
Evaluating Small UAS Operations and National Airspace System Interference Using AeroScope
}

\author{
Ryan J. Wallace, Kristy M. Kiernan, and John Robbins \\ Embry-Riddle Aeronautical University
}

Tom Haritos

Kansas State University

Jon M. Loffi

Oklahoma State University

\begin{abstract}
A recent rash of near mid-air collisions coupled with the widespread proliferation of small unmanned aircraft systems (sUAS) raise concerns that integration is posing additional risk to the National Airspace System. In 2016, sUAS sighting reports by manned aircraft pilots averaged 147 per month. In the first three quarters of 2017, sUAS sightings jumped to 188 per month. The purpose of this study was to evaluate sUAS operator behavior to determine potential interference with aviation operations. While previous research has indeed yielded findings about operator behavior, such studies were generally based on data derived from Aviation Safety Reporting System filings or the UAS sighting report database maintained by the Federal Aviation Administration. In this study, the authors partnered with a UAS technology company to deploy an AeroScope, a passive radiofrequency detection device, to detect UAS flight activity in an urban area. While the device was limited to collecting flight information from only DJImanufactured platforms, it is estimated that the company holds a market share in excess of $70 \%$ providing a reasonable barometer for sUAS activity in the sample area. Over the 19-day sample period, the AeroScope device recorded 258 detections of 77 unique sUAS platforms. The authors assessed sUAS operator behavioral characteristics, including: UAS models, operating altitudes, preferred flying days and times, flight durations, and operating locations. The authors assessed 93 potential violations of 14 CFR 107 regulations, including controlled airspace breaches, exceeding maximum flight altitudes, and flight outside of daylight or civil twilight hours. The authors concluded that UAS activity in the sample area posed potential conflicts with a runway visual approach, created a collision hazard with three heliports, and heightened risk for visual flight rules operations underneath a controlled airspace shelf. The authors determined existing sUAS geofencing systems were ineffective at deterring sUAS activity unless they imposed flight restrictions in addition to hazard notification.
\end{abstract}

Keywords: $\quad$ small unmanned aircraft systems (sUAS), drone, near mid-air collision (NMAC), airspace, AeroScope, DJI 


\section{Introduction}

As of October 31, 2017, there were 836,796 hobbyists registered as model aircraft operators in the United States (Gettinger \& Michel, 2017). The hobbyist fleet of unmanned aircraft is forecasted to top 2.4 million by 2022 (Federal Aviation Administration [FAA], 2018). Similarly, the population of commercial unmanned aerial system (UAS) platforms is expected to increase from 110,604 at the end of 2017 to 450,000 by 2022 (FAA, 2018). With the rapid rise in both hobbyist and commercial UAS, there has been a corresponding uptick in near encounters between unmanned aircraft and manned aircraft. In 2016, the FAA received 1,762 reports of UAS sightings by aircrew members, representing an average sighting rate of 147 incidents per month (FAA, 2019). By September 2017, there had been 1,699 reported UAS sightings, representing an average of 188 incidents per month (FAA, 2019).

Perhaps more alarming than the raw number of unmanned aircraft sightings by manned aircraft are the locations of these sightings. In a study by Gettinger and Michel (2015), of the 921 reported UAS sightings between December 17, 2013 and September 12, 2015, more than $90 \%$ occurred in areas where unmanned aircraft were forbidden. Gettinger and Michel (2015) determined that 90.2\% ( $n=708, N=785$ in which altitude was reported) of encounters occurred more than $400 \mathrm{ft}$ above ground level (AGL), and 58.8\% $(n=391)$ occurred within $5 \mathrm{mi}$ of an airport. In $17 \%(n=158)$ of the incidents, manned and unmanned aircraft came within $200 \mathrm{ft}$ or less of each other. The highest number of incidents generally occurred in large urban areas between the hours of 10:00am and 6:00pm (Gettinger \& Michel, 2015).

A subsequent archival study using Aviation Safety Reporting System data from 1993 to 2016 revealed that $96.5 \%(n=164)$ of reported UAS incidents occurred within controlled or special use airspace (Sharma, 2016). This seems to confirm the findings of Gettinger and Michel (2015), which suggested that a substantial number of incidents were clustered around large urban locationsmany of which are encompassed within highly congested Class B or C airspace. In the Gettinger and Michel (2015) study, nearly $9.3 \%(n=86)$ of the 921 incidents recorded occurred within the Class B airspace surrounding Newark Airport, New Jersey. At least 39 reported UAS encounters occurred in Los Angeles, which has high-traffic Class B airspace around Los Angeles International Airport, as well as four additional airports surrounded by congested Class C airspace (Gettinger \& Michel, 2015). Of the 39 reported UAS sightings in Los Angeles, 17 occurred within $10 \mathrm{mi}$ of the approach paths to runways $25 \mathrm{~L}$ and $25 \mathrm{R}$ (Gettinger \& Michel, 2015).

The increased numbers of aircraft encounters with UAS have gained FAA attention, and in October of 2015, the agency partnered with CACI International to evaluate technological solutions to detect and identify unmanned aircraft operating around airports (FAA, 2016a). Between January 25 and February 2, 2016, the agency conducted testing of a CACI radiofrequency detection system at Atlantic City International Airport along the eastern seaboard of New Jersey (FAA, 2016a). Atlantic City lies within Class $C$ airspace, less than 40 nautical miles from Philadelphia International Airport and 80 nautical miles from JFK International Airport in New York. During the five-day test, the CACI system detected a total of 141 UAS operations, which included 72 indications of UAS activation on the ground and 69 UAS platforms in flight (FAA, 2016a).

\section{Purpose}

This research was the first of a series of studies the authors performed to assess the extent of the problem of unmanned aircraft flight interference with aviation operations. In this study, the authors sought to quantify the number of unmanned aircraft flights near airports in and around congested Class B airspace. The authors compared detected aircraft flight patterns and observations against local aeronautical information, such as aerodromes, traffic patterns, approaches, and other related information, to present potential or realized interference created by unmanned aircraft flight patterns. Additionally, the authors examined UAS operator launch locations to identify common characteristics and flight location favorability factors. Finally, the authors evaluated the number of small UAS (sUAS) flights that occurred despite geofencing restrictions. This research differs from previous studies because the researchers did not perform proof-of-concept or penetration testing. Data collected during this study represented actual UAS operations in the test area-none of which were influenced by the research team.

\section{Research Questions}

The authors sought to answer the following research questions:

1. What are common characteristics of UAS flight locations?

2. What are common characteristics of UAS operations (including UAS platform type, date/time of operation, flight duration, and maximum altitude)?

3. What is the potential impact of detected unmanned aircraft activity on aerodromes and aviation operations?

4. How effective are geofencing restrictions in preventing UAS flights into protected areas?

\section{Literature Review}

In 2017, UAS manufacturer DJI unveiled a device known as the AeroScope, which detects, identifies, and 
monitors unmanned aircraft (see Figure 1). The AeroScope is a passive radiofrequency sensor that eavesdrops on existing datalinks between DJI unmanned aircraft and remote pilot controllers, and displays and records their flight information (DJI, 2017a). The AeroScope collects telemetry of DJI UAS platform activity within electronic line of sight, including location of the unmanned vehicle, location of the remote controller, flight path, altitude, speed, direction, and other parametric details (DJI, 2017a).

To aid UAS operators in determining where it is safe to fly, DJI incorporates GEO zone-more commonly referred to as geofencing - restrictions into its programming. DJI (n.d.) describes the role of GEO zones on the company's website:

DJI's GEO System delineates where it is safe to fly, where flight may raise concerns, and where flight is restricted. GEO zones that prohibit flight are implemented around locations such as airports, power plants, and prisons. They are also implemented temporarily around major stadium events, forest fires, or other emergency situations. Certain GEO zones don't prohibit flight, but do trigger warnings that inform users of potential risks. (p. 1)

The GEO zone system restricts UAS operations within or into areas that would create a security or safety risk (DJI, n.d.). For areas that do not involve national security, users are capable of self-authorizing flights by unlocking restrictions via a verified DJI account (DJI, n.d.). DJI's GEO zones offer four categories of protection:

Warning Zones: Users are prompted with a warning message in the UAS user interface regarding operations in a specified area (DJI, n.d.).

Enhanced Warning Zones: Users are prompted with a warning message in the UAS user interface and flight is restricted. This limitation may be overridden by the user in the user interface (DJI, n.d.).

Authorization Zones: Areas are displayed in yellow and users are prompted with a warning message in the UAS user interface and flight is restricted. This limitation may be overridden by the user by overriding the restrictions with a verified DJI account (DJI, n.d.).

Restricted Zones: Areas are displayed in red and users are prompted with a warning message in the UAS user interface and flight is prevented. Unlock access is only available via coordination with DJI (DJI, n.d.).

Restricted Zones come in two variants-Airport Restricted Zones and other Restricted Zones. Airport Restricted Zones are modeled with an interior, circular perimeter that prohibits takeoff and flight within an established radius of the center point. According to DJI (2017b), the radius of the interior perimeter "depends on the size and shape of the airport" (p. 59). Beyond the radius of the interior Airport Restricted Zone, flight is limited to an altitude of $66 \mathrm{ft}(20 \mathrm{~m})$ and extending outward at a $15^{\circ}$ inclination up to a maximum of $1,640 \mathrm{ft}$ and out to a

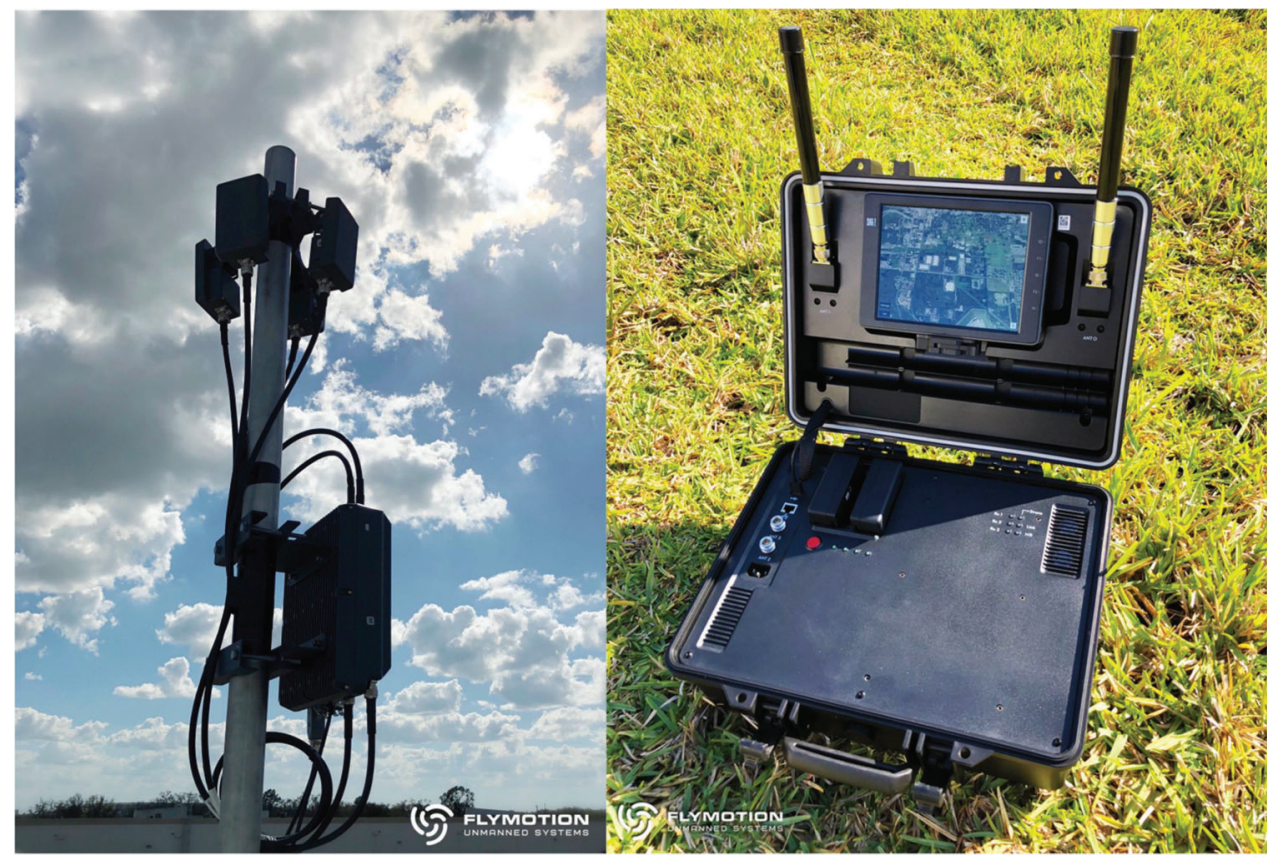

Figure 1. (Left) Permanent AeroScope radiofrequency detection device. (Right) Mobile AeroScope in Pelican case. Images courtesy of FLYMOTION. Used with permission. 
distance of $1 \mathrm{mi}$ (DJI, 2017b). Within $0.062 \mathrm{mi}(100 \mathrm{~m})$ of the aerial vehicle approaching a restricted zone, the operator will receive an alert message on the DJI user interface (DJI, 2017b). Conversely, a Restricted Zone is established for other protected areas. These zones do not have altitude restrictions and extend outward to form a circular perimeter, which may vary based on the established restriction. Similar to Airport Restricted Zones, users receive an alert when the aerial vehicle approaches within $0.062 \mathrm{mi}(500 \mathrm{~m})$ of a Restricted Zone.

\section{Method}

This applied research project used a combination of exploratory research and case study design methodology. The authors partnered with a UAS technology company to secure access to a DJI AeroScope. The authors evaluated data collected over a 19-day period by the DJI AeroScope, which was deployed at an elevation of $45 \mathrm{ft}$ AGL atop a commercial building in Tampa, Florida. The authors examined detected UAS information including the type and number of individual platform detections, detection location, maximum flight altitude, flight duration, and time of operation to form conclusions about UAS operator behavior. Altitude data were recorded in mean sea level (MSL) for consistency and, when required, were converted to AGL. The authors analyzed collected information by plotting detection location using Google Earth Pro. Geolocation data were converted to compatible KML format using EasyMapMaker, an online geolocation tool designed to create custom Google maps. Aeronautical chart data were extracted from the Tampa Terminal Area Chart obtained from the FAA Sectional Aeronautical Raster Charts website. Aeronautical information regarding private heliports was acquired from the AirNav website. Additional geolocation information regarding geofencing data was acquired from the DJI Fly Safe Geo Zone Map website.

\section{Findings and Discussion}

The AeroScope collected data from February 18, 2018 to March 2, 2018 and again from March 23 to 28, 2018. Detection ranged between 0.01 statute miles (SM) to as far away as 10.78 SM from the AeroScope deployment location. More than $95 \%$ of the detections were located within 6.0 SM of the AeroScope device.

\section{Platform Type}

The AeroScope detected 77 unique platforms which included 2 Matrice (200-series only), 5 Inspire (all models), 22 Phantom 4 (all variants), 4 Phantom 3 (all variants), 27 Mavic Pro, 14 Spark, and 3 unknown platforms. A census of detected models is depicted in Figure 2.

\section{Individual Detections}

During the sampling period, the AeroScope recorded 320 UAS detections. A detection is defined as a unique exposure that produced a separate log in the AeroScope data. Each detection included a defined start and stop time. An overview of UAS detections is provided in Figure 3.

In some cases, detections were not continuous. This likely occurred when a sUAS flight was landed for a battery swap or when an obstruction between the sUAS and AeroScope interrupted receipt of the datalink communication signal.

Of the 320 original detections, 50 logs were removed because they lacked location information. An additional $12 \operatorname{logs}$ were removed because they fell outside the geographical area of the AeroScope deployment location due to the AeroScope being temporarily used by the company for a roadshow demonstration. The findings were modified to accurately reflect collection dates. The remaining $258 \operatorname{logs}$ formed the basis of the data analysis.

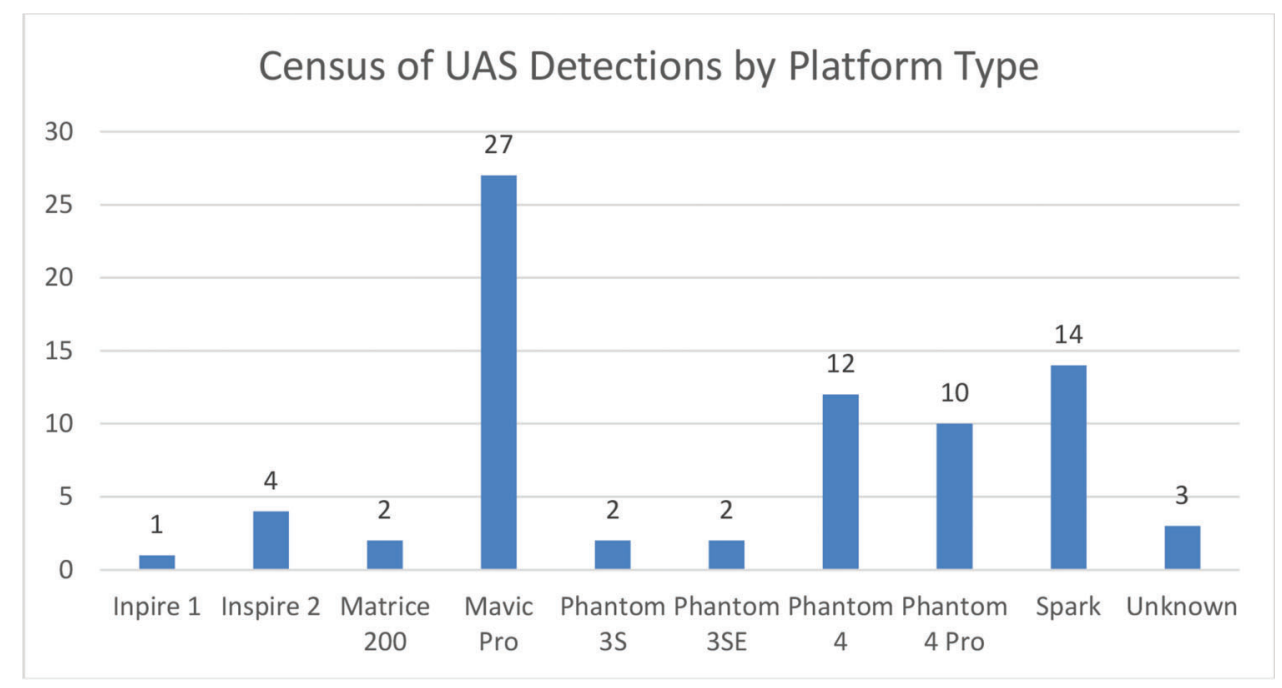

Figure 2. Census of detected platforms by model. 
Detections by Day of Week

The researchers aggregated the daily results based on the number of sampled days, yielding a daily average. The average daily detection rate is presented in Figure 4.

Using historical data, researchers assessed weather data including wind, visibility, and precipitation to determine days in which adverse weather was likely to influence UAS flight. Over the course of the 19-day sampling period, the weather was extremely stable, with wind less than 10 knots, visibility greater than $5 \mathrm{SM}$, and a maximum of 0.1 inches of daily precipitation (Weather Underground, 2018). Based on these findings, the researchers assessed that weather conditions were generally favorable for UAS flight throughout the testing period.

\section{Detection Time}

UAS flights were detected between 5:32am and 11:31pm local time. Figure 5 depicts the distribution of UAS flights by detection time.
Based on the collected data, the authors determined that two UAS flights were conducted prior to the civil twilight window-one at 6:19am on March 24 and one at 5:32am on February 25. At least 40 UAS detections occurred after the period in which civil twilight ended (FAA, n.d.a). This culminates in $16.3 \%(n=42)$ of total UAS detections occurring outside of 14 CFR 107.29 limitations.

\section{Maximum Altitude}

The maximum altitude of detected UAS flights ranged from 0 to $1,606 \mathrm{ft}$ MSL. Note that DJI UAS platforms are limited to a maximum flight altitude of 1,640 ft $(500 \mathrm{~m})$, based on programmed flight limitations. The AeroScope recorded a maximum altitude of $0 \mathrm{ft}$ for 50 of the 258 data points. Of the 258 data points, 81.0\% $(n=209)$ recorded a maximum altitude of $400 \mathrm{ft}$ or less. Nineteen percent $(n=49)$ of UAS flights were conducted in excess of $400 \mathrm{ft}$ MSL. The highest reported airfield elevation within the data coverage area was $26 \mathrm{ft}$ MSL at Tampa International Airport. When integrating the 26-foot MSL correction, 47 flights were conducted above

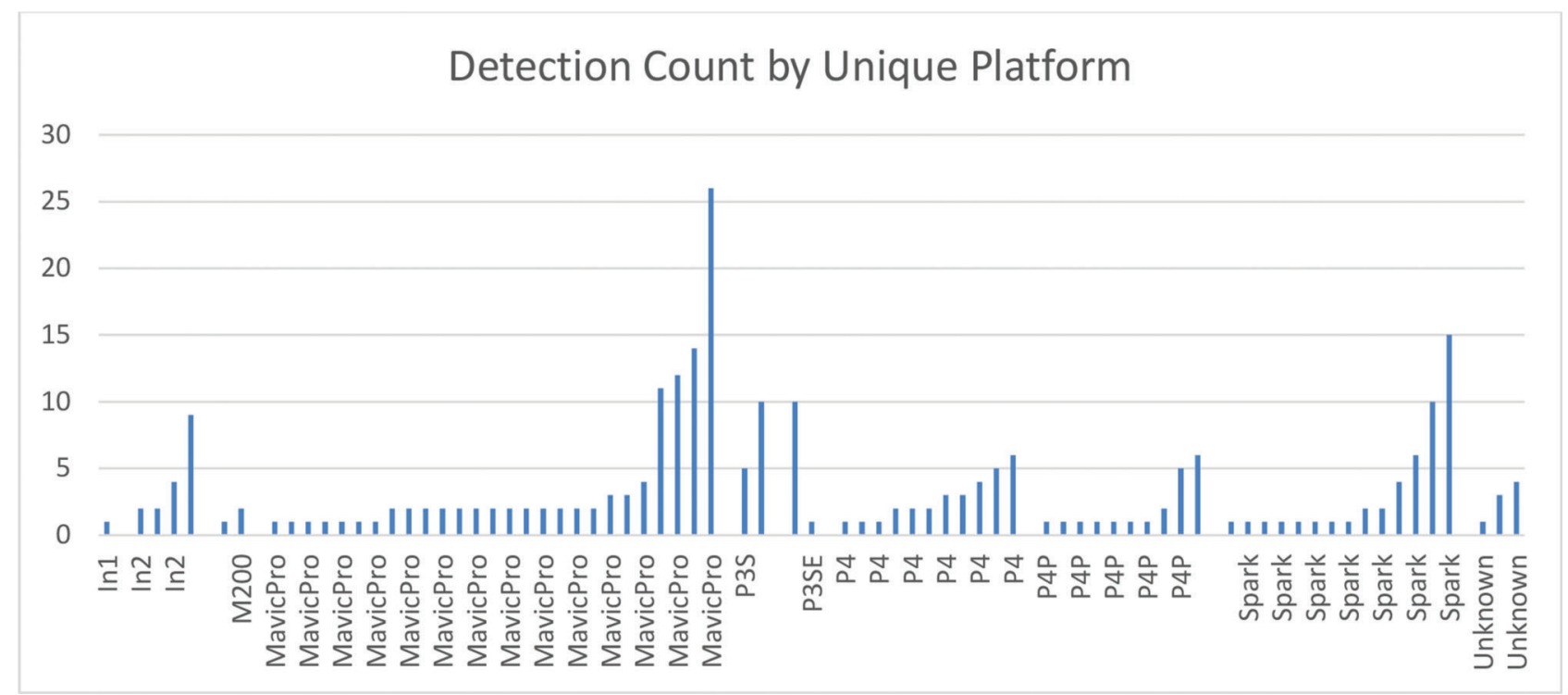

Figure 3. Detection count by unique platform.

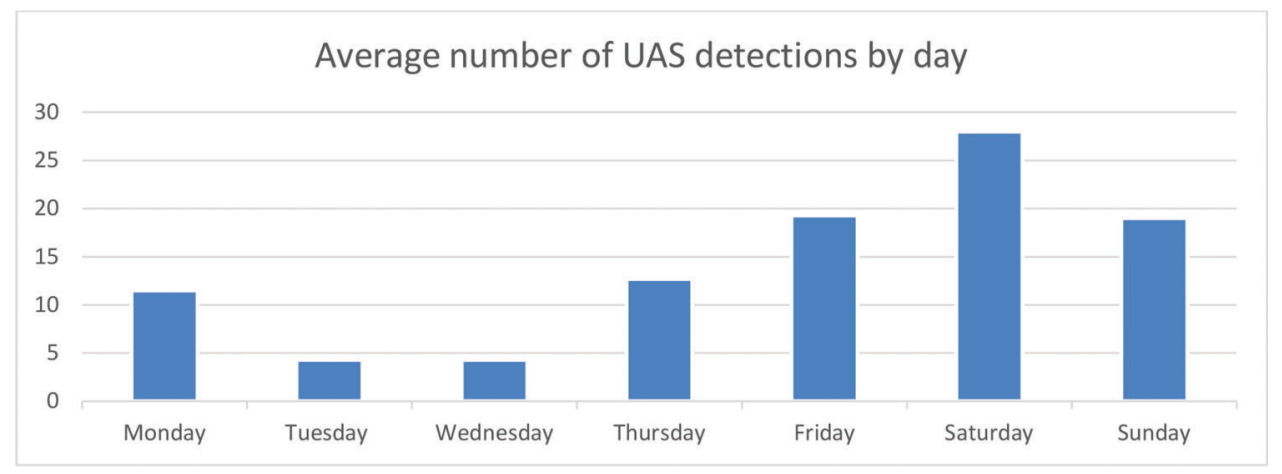

Figure 4. Average number of detections per day. 


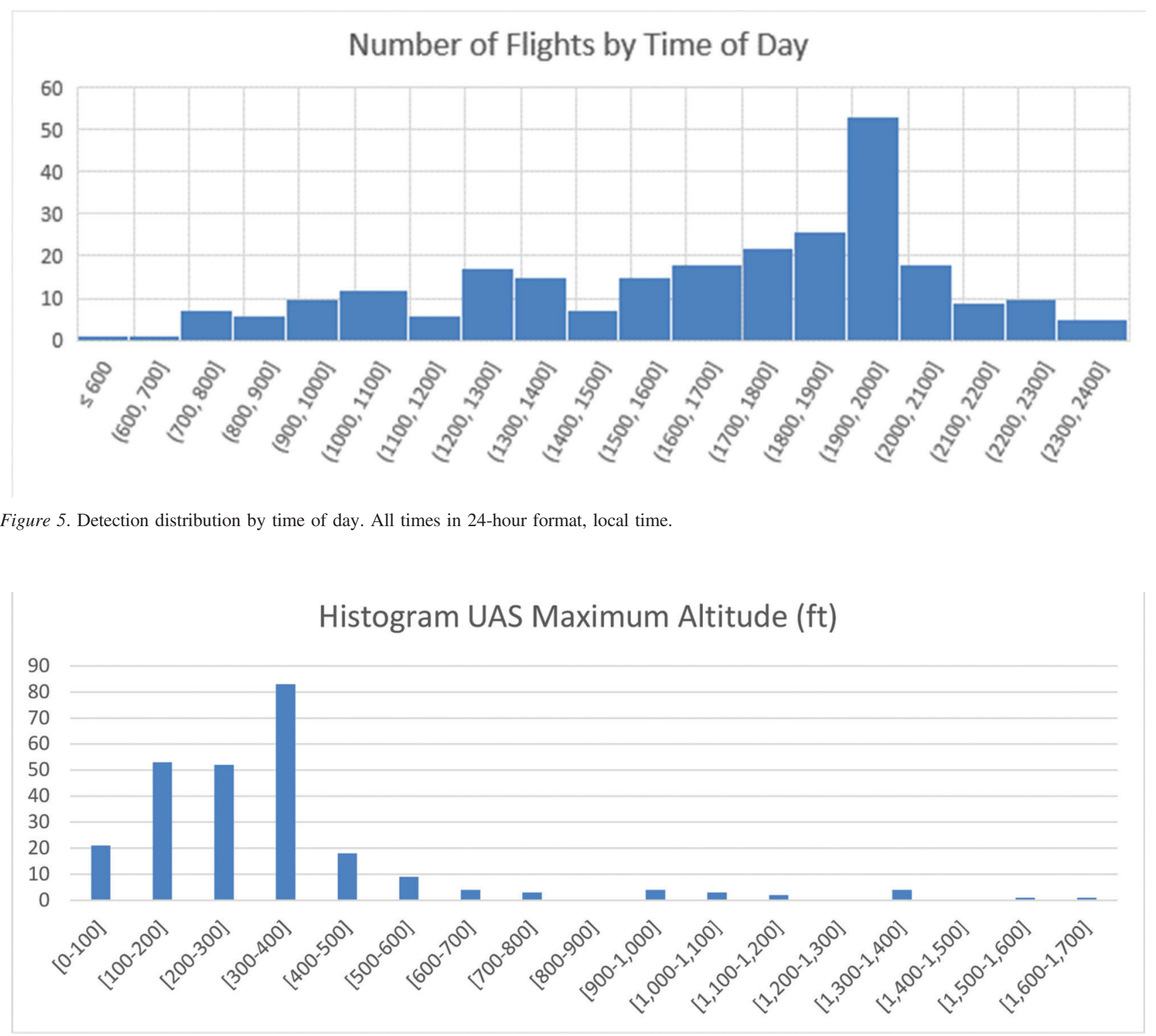

Figure 6. Maximum altitude of detected UAS sorties.

$426 \mathrm{ft}$ MSL (approximately $400 \mathrm{ft}$ AGL), exceeding sUAS maximum altitude requirements codified in $14 \mathrm{CFR}$ 107.51(b) (without regard sub-provisions $1 \& 2$ ). At least $11.6 \%(n=30)$ of the UAS sorties were conducted above $526 \mathrm{ft}$ MSL (approximately $500 \mathrm{ft}$ AGL) - the lowest altitude over non-congested areas at which manned aircraft can fly, based on 14 CFR 91.119 rules. The distribution of detected maximum flight altitudes is presented in Figure 6.

\section{Flight Duration}

The flight duration of detected platforms ranged between 0 and 3,338 s (55:38). Of the 258 data points, 80 recorded a flight duration of $0 \mathrm{~s}$. The mean flight duration was $113 \mathrm{~s}$ with the median flight duration being $31 \mathrm{~s}$. When assessed with all durations of $0 \mathrm{~s}$ removed, the mean flight time was $161 \mathrm{~s}(2: 41)$, and the median time was $62 \mathrm{~s}$ (1:02). The distribution of UAS flight durations is presented in Figure 7. This was an unexpected finding, considering the endurance of most DJI platforms exceeds $25 \mathrm{~min}$. One possible explanation for this finding is that the sUAS passed out of the AeroScope's electronic line of sight prior to the conclusion of the flight.

\section{Flight Duration Proportion of Design Maximum}

Since flight duration is a function of platform capabilities such as battery capacity, flight characteristics, weight, and other factors, flight duration data were further assessed by platform type. Results are presented in Figure 8. Table 1 depicts mean and median flight durations for each platform type, as well as maximum flight durations, based on 
information derived from the DJI product specifications website. A reasonable estimation of average power utilization can be derived from the Percent of Maximum category in Table 1. Figure 9 depicts the distribution of detected UAS flight durations by platform as a function of the platform's maximum flight time specifications reported by DJI.

\section{Operating Location}

The authors assessed the locations where detected UAS were operated using a descriptive categorization taxonomy. Figure 10 depicts sUAS detections within the sample area, with an accompanying heat map showing the density of sUAS detections. Four researchers independently coded the 258 locations with coding results correlated to improve accuracy. Findings indicated that $38 \%(n=$ 97) - the largest proportion of UAS operators-flew in proximity to single-family structures. At least $27 \%$ ( $n=$ 69) of detected UAS flights were conducted near commercial or industrial locations. Such flights were generally initiated from parking lots or other open areas near these facilities. It is also notable that $12 \%(n=32)$ of UAS flights occurred on public property, such as roadways or public parks. The remaining $23 \%$ of UAS detections were

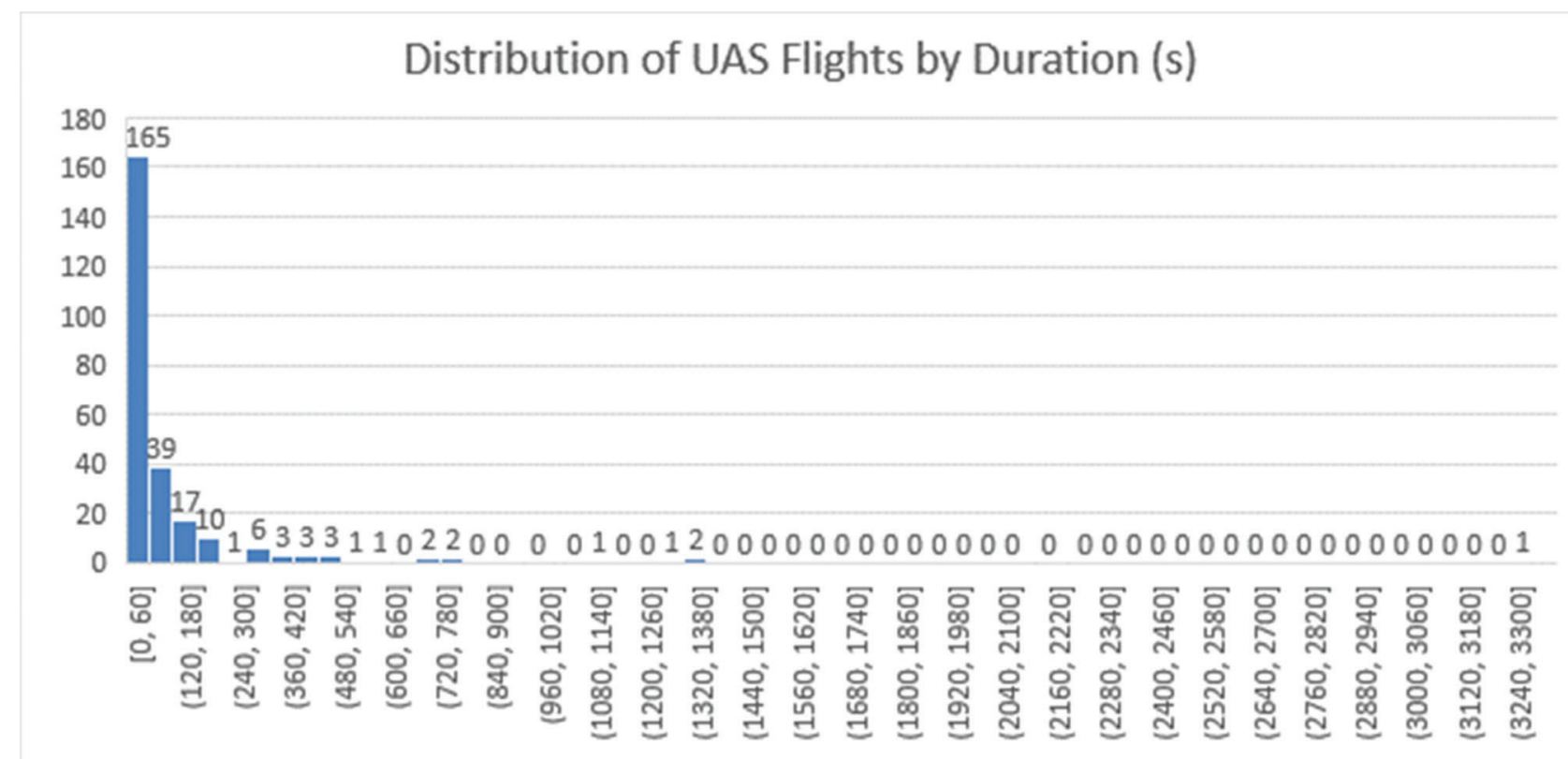

Figure 7. Duration of detected UAS sorties (in seconds). Note: major axis marks are presented in 60-second (1-minute) intervals.

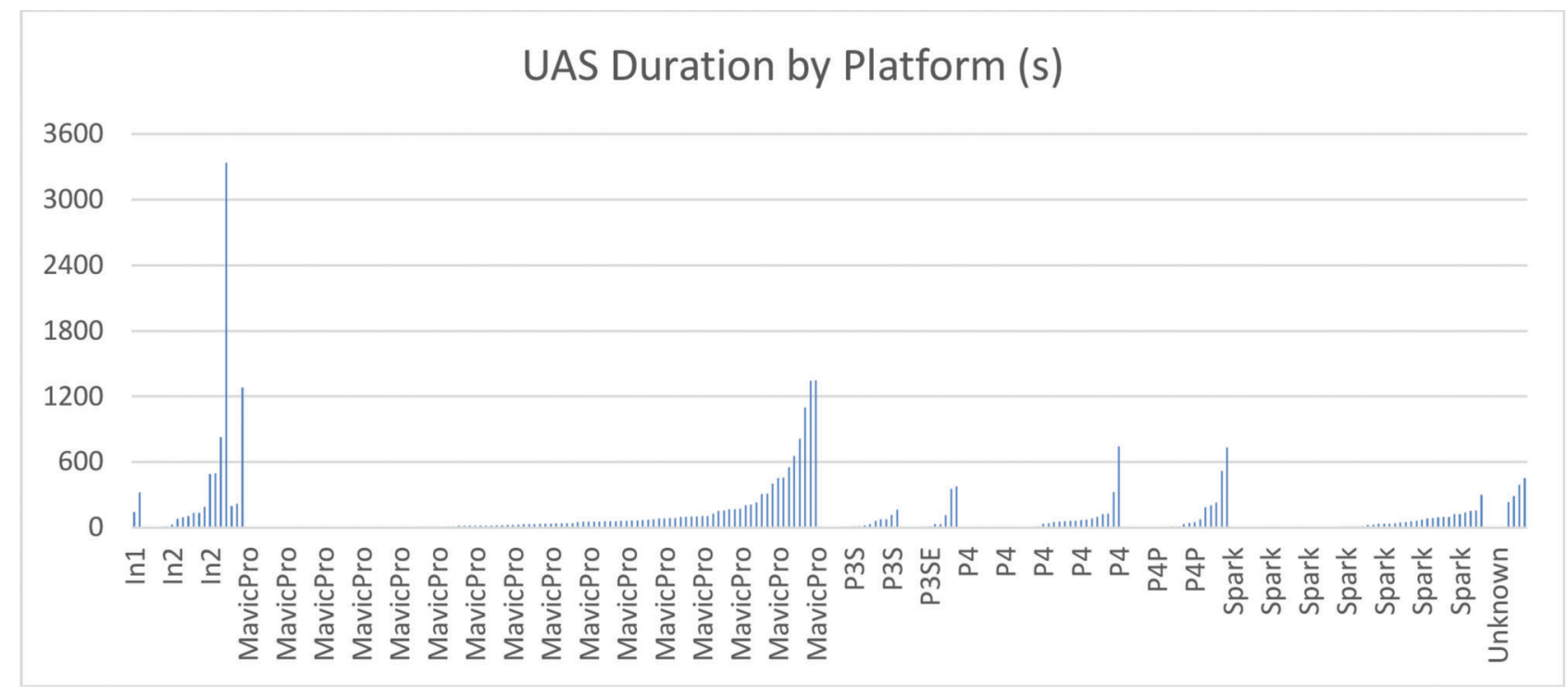

Figure 8. Duration of detected UAS sorties (in seconds) by platform model. Note: major axis marks are presented in 10-minute (600-second) intervals. 
made over unimproved land, waterways, multi-family homes, stadiums, and other uncategorized structures. A complete assessment of operator locations is provided in Figure 11.

\section{Aeronautical Impact Assessment}

Of the 258 data points, two sUAS appeared to penetrate the Tampa International Airport Class B surface area (see Figure 12). Two additional aircraft penetrated the Tampa Class B shelf at the 1,600 and 1,400 ft levels. While Peter O. Knight Airport lies in Class G airspace, there was substantial UAS activity (more than 60 detections) within 3 SM of the airfield. While not depicted on the Tampa Terminal Area Chart, it was notable that a substantial number of UAS

Table 1

Summary statistics of UAS flight duration by platform.

\begin{tabular}{lrrrrrr}
\hline Platform & Mean & $\begin{array}{c}\text { (\% of } \\
\text { Max.) }\end{array}$ & Median & $\begin{array}{c}(\% \text { of } \\
\text { Max. })\end{array}$ & SD & Max. \\
\hline Inspire 1 & 233.0 & $(21.6 \%)$ & 233.0 & $(21.6 \%)$ & 124.5 & 1080 \\
Inspire 2 & 424.8 & $(26.2 \%)$ & 121.0 & $(7.5 \%)$ & 872.3 & 1620 \\
Matrice 200 & 567.0 & $(24.9 \%)$ & 221.0 & $(9.7 \%)$ & 619.3 & 2280 \\
MavicPro & 157.1 & $(9.7 \%)$ & 60.0 & $(3.7 \%)$ & 273.3 & 1620 \\
Phantom 3 Std & 49.9 & $(3.3 \%)$ & 27.0 & $(1.8 \%)$ & 50.9 & 1500 \\
Phantom 3 SE & 129.5 & $(8.9 \%)$ & 62.0 & $(2.3 \%)$ & 169.6 & 1500 \\
Phantom 4 & 161.9 & $(7.7 \%)$ & 53.0 & $(3.7 \%)$ & 224.9 & 1680 \\
Phantom 4 Pro & 353.6 & $(9.0 \%)$ & 186.0 & $(2.9 \%)$ & 516.4 & 1800 \\
Spark & 67.6 & $(7.0 \%)$ & 49.0 & $(5.1 \%)$ & 64.8 & 960 \\
Unknown & 342.3 & & 340.5 & & 99.6 & N/A \\
\hline
\end{tabular}

Note. All data depicted in seconds. Maximum values derived from DJI product specifications website by platform. Maximum values were presumed to equate to battery exhaustion, in which controllability and/or safe flight was compromised. When multiple maximum values were provided based on varying flight conditions, the longest duration was selected. detections (60) occurred within $2 \mathrm{SM}$ of three clustered heliports (54FL, FL70, and 61FL). Another heliport of concern was 9FD6, for which 46 detections were made within a 2 SM radius. The Mezrah private seaplane base also had a notable number of UAS detections (16) within a 1.5 SM radius.

The interior ring of the Tampa Class B shelf compresses certain general aviation operations below 1,200 ft east of Tampa International Airport and MacDill AFB. Coupled with the finding that $11.6 \%$ of UAS flights occurred above $500 \mathrm{ft}$ AGL, these conditions suggest that near encounters between manned and unmanned aircraft are likely as non-compliant UAS operations encroach into this congested airspace.

Clustering of unmanned aircraft activity occurs $1.4 \mathrm{SM}$ north of Peter O. Knight Airfield, and aligning directly with a visual approach to Runway 18, as presented in Figures 13 and 14 . Trigonometric calculation of a standard $3^{\circ}$ glideslope to the Runway 18 threshold suggests that at a distance of $1.4 \mathrm{SM}$, a descending aircraft would be at an altitude of approximately $387 \mathrm{ft}$ AGL. Within the cluster area, researchers counted 17 UAS detections that occurred between 300 and $400 \mathrm{ft}$ AGL. It is likely that visual detection of a sUAS during this approach would be problematic, as an encounter would likely occur as the aircraft is performing a southbound maneuver. The maneuver aligns the aircraft with the runway to avoid inadvertent penetration of the Tampa Class B surface area to the northwest. Of collisions between manned aircraft, $88 \%$ occur when at least one aircraft is maneuvering (Morris, 2005); therefore, an aircraft maneuvering for approach in this area may be particularly vulnerable.

\section{Heliport activity in downtown Tampa}

Twelve UAS detections occurred within proximity to three heliports in downtown Tampa, including Tampa

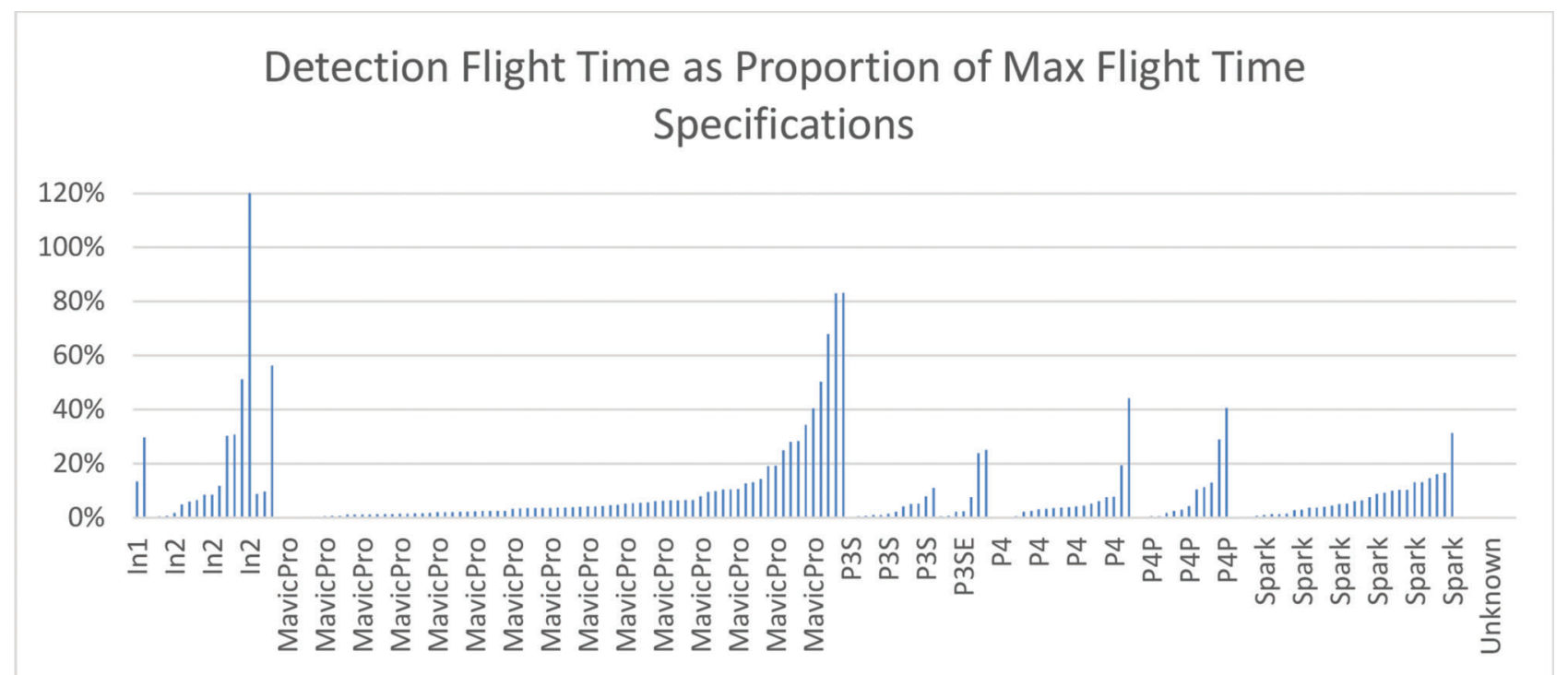

Figure 9. Detected flight time as proportion of maximum flight time specification by platform. Note: one Inspire 2 flight detection time represented $206 \%$ of reported maximum specification. Depiction of this outlier was capped at $120 \%$ on this graphic. 

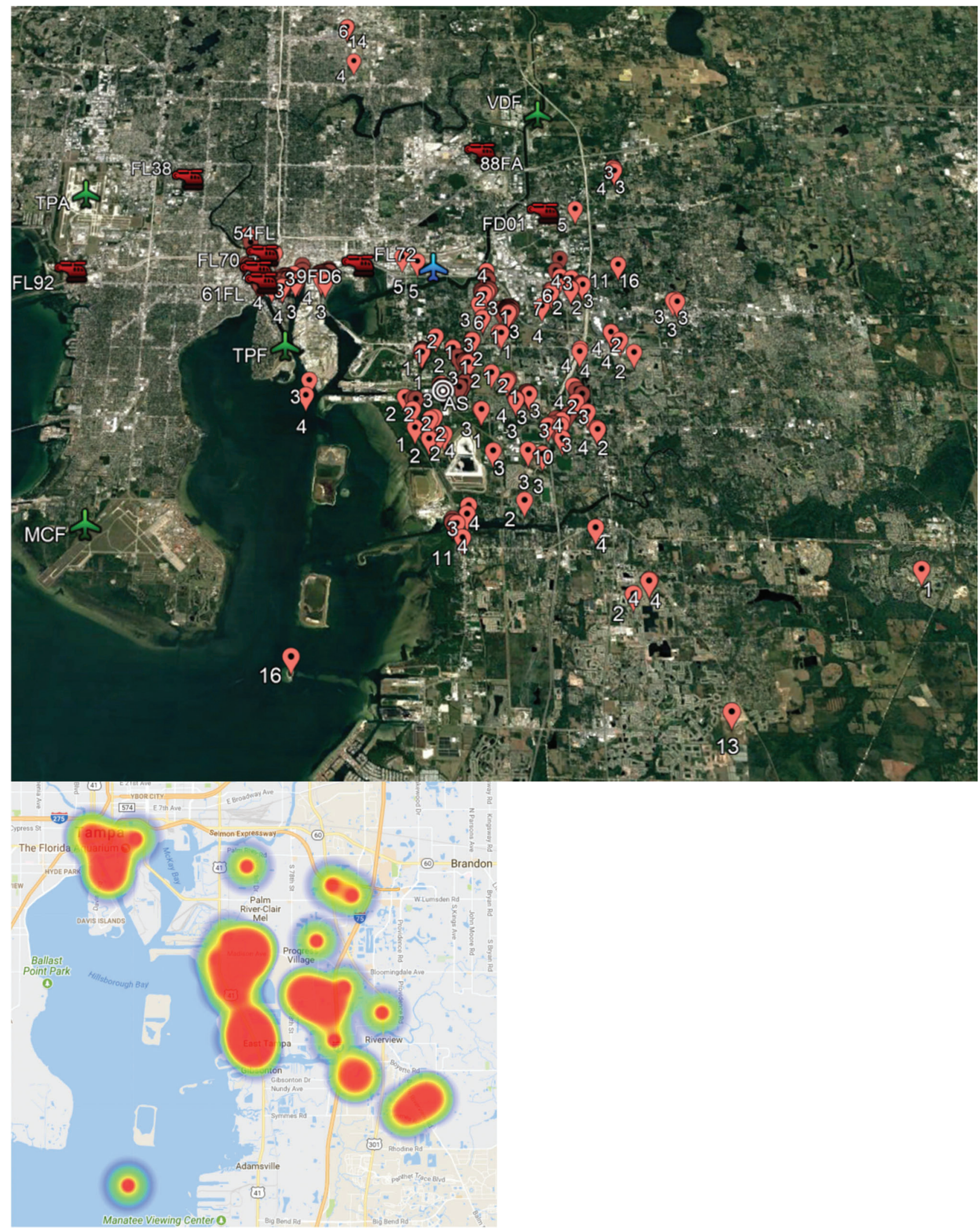

Figure 10. (Top) AeroScope detection data (Tampa, FL). Note: red pins represent individual UAS sortie detection logged by the AeroScope device during the collection period. Numerals adjacent to the pins represent rounded altitude information in hundreds of feet. All aerodromes within the detection area are labeled with their respective ICAO identifiers. Airports are represented by a green aircraft symbol, seaplane bases with a blue aircraft symbol, and heliports with a red helicopter symbol. The AeroScope sensor is depicted as a white target in the center of the graphic. (Left) Heat map of AeroScope UAS detections. Image courtesy of FLYMOTION. Used with permission. 


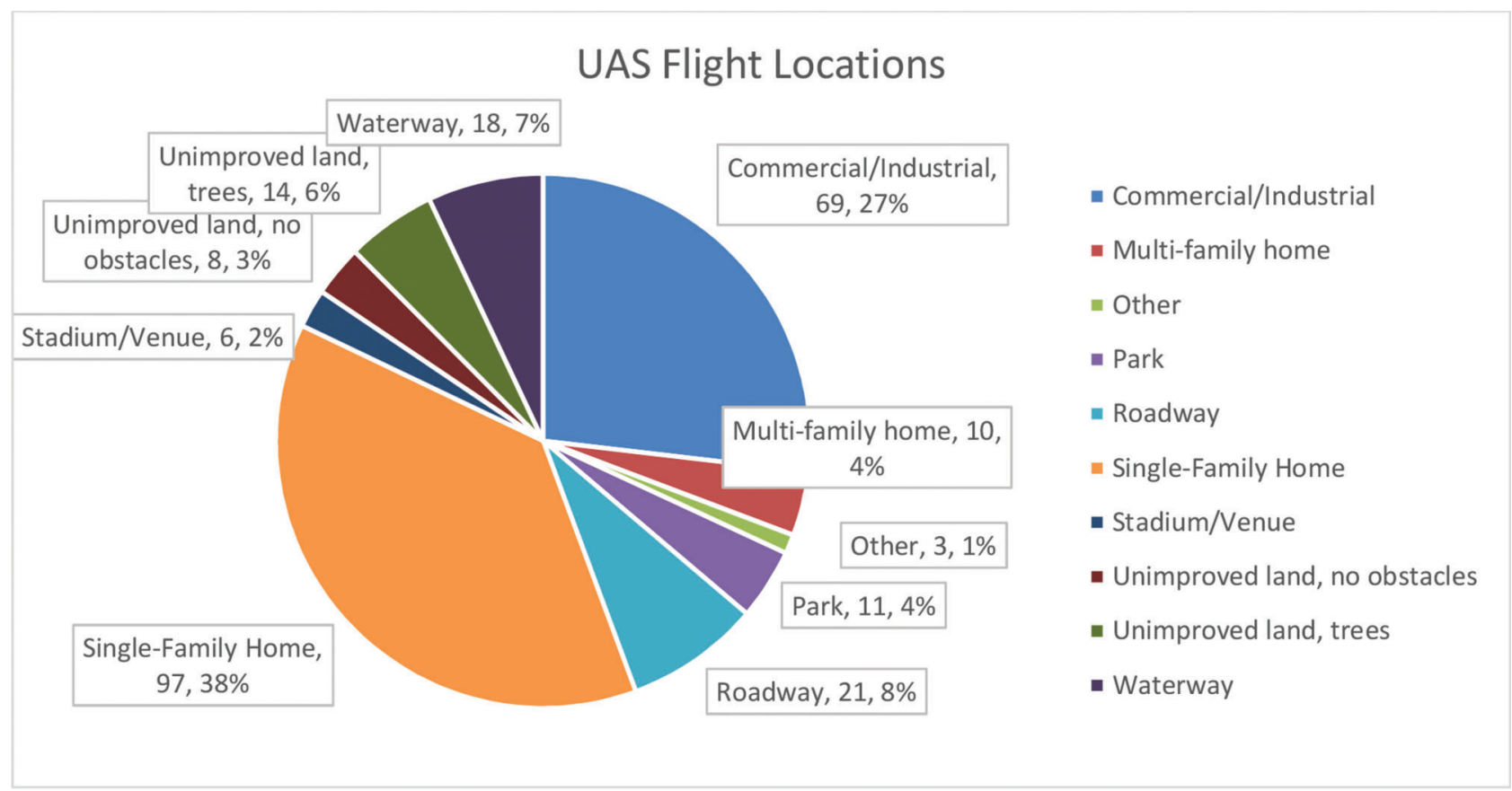

Figure 11. Detected UAS activity by location type.

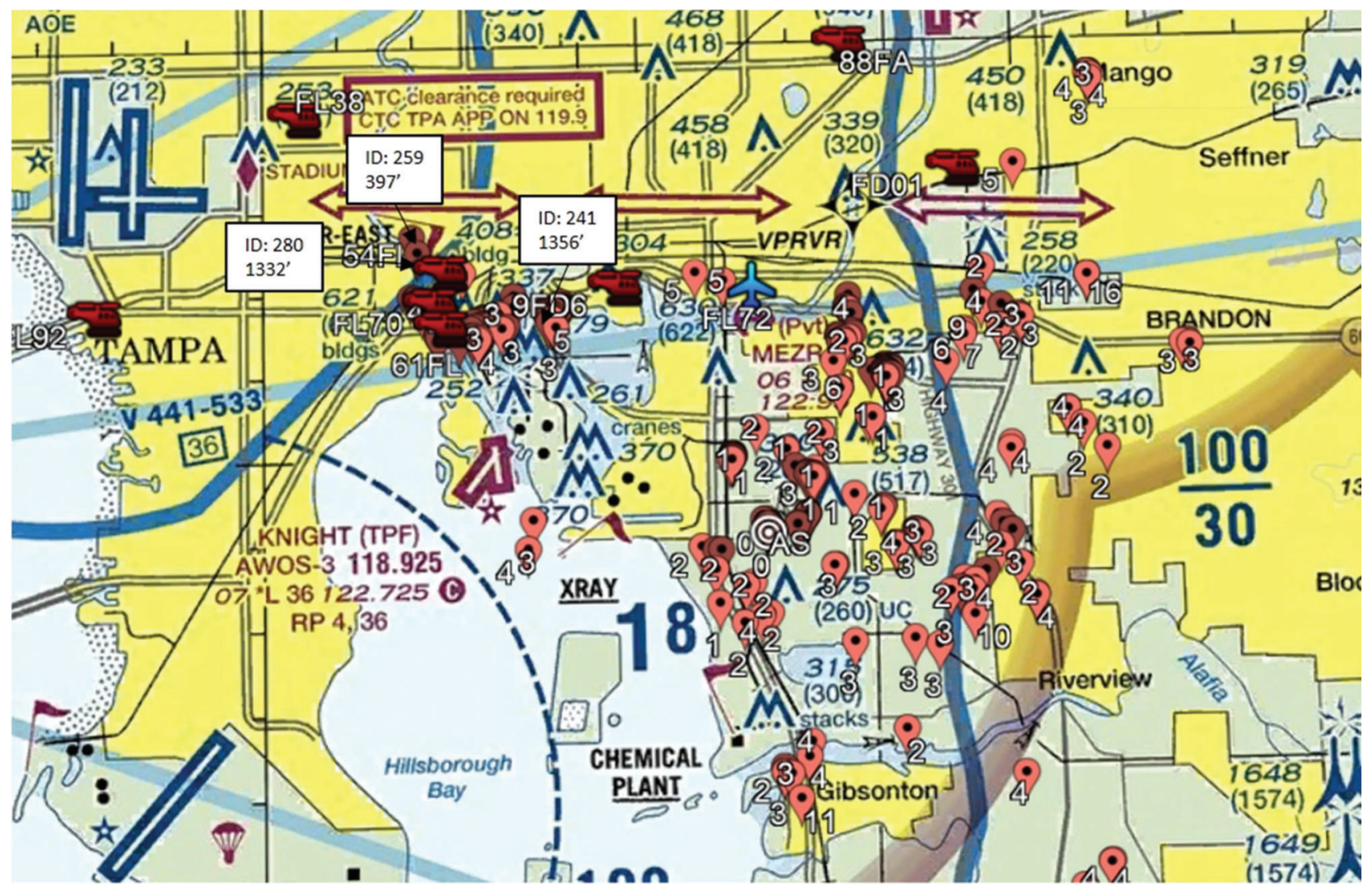

Figure 12. AeroScope detection data overlaid on Tampa Terminal Area Chart. Numerals adjacent to the pins represent rounded altitude information in hundreds of feet (MLS). Heliports are depicted with a red helicopter symbol. The AeroScope sensor is depicted as a white target in the center of the graphic. Suspected airspace violations are identified by their record number, altitude, and pointer to detection location. 


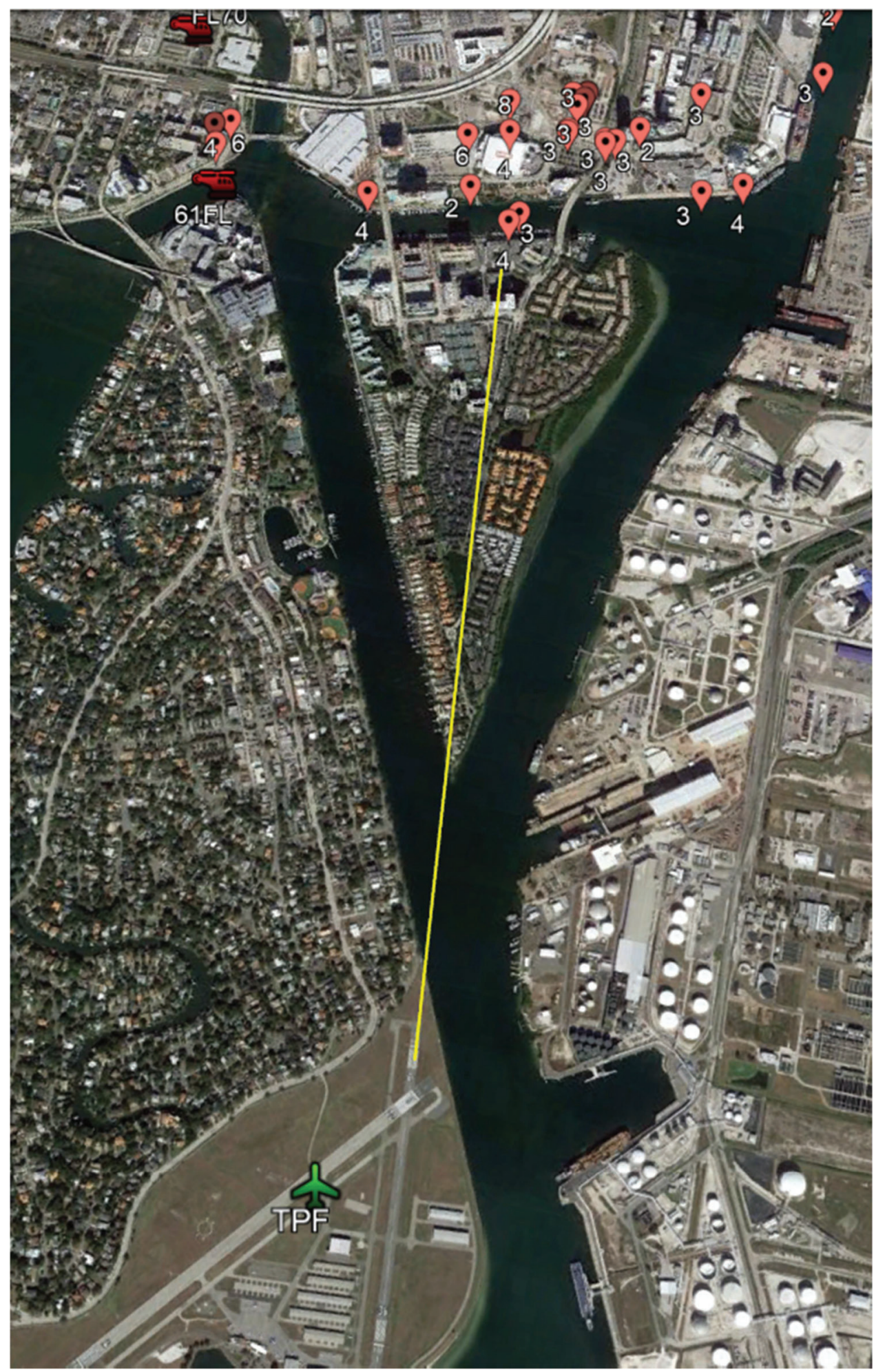

Figure 13. Visual approach path to Peter O. Knight (TPF) Runway 18. Yellow line extends from threshold (Runway 18 has a displaced threshold) along runway orientation to $1.4 \mathrm{SM}$. At the northern end of the yellow line, an aircraft performing a standard $3^{\circ}$ approach would be at approximately $387 \mathrm{ft}$ AGL, based on trigonometric calculations. Assuming detected activity is representative of normal UAS flight operations north of Harbour Island, this condition would likely put approaching aircraft coming into Runway 18 at a risk of midair collision.

General Hospital (61FL), WFLA-TV 8 (FL70), and Teco Plaza (54FL). Results are displayed in Figure 15. Although DJI incorporates geofencing within a 0.10 SM radius around each of these locations, they are only Warning Zones, which provides an informational prompt to the UAS operator but does not restrict flight activity. It is also 


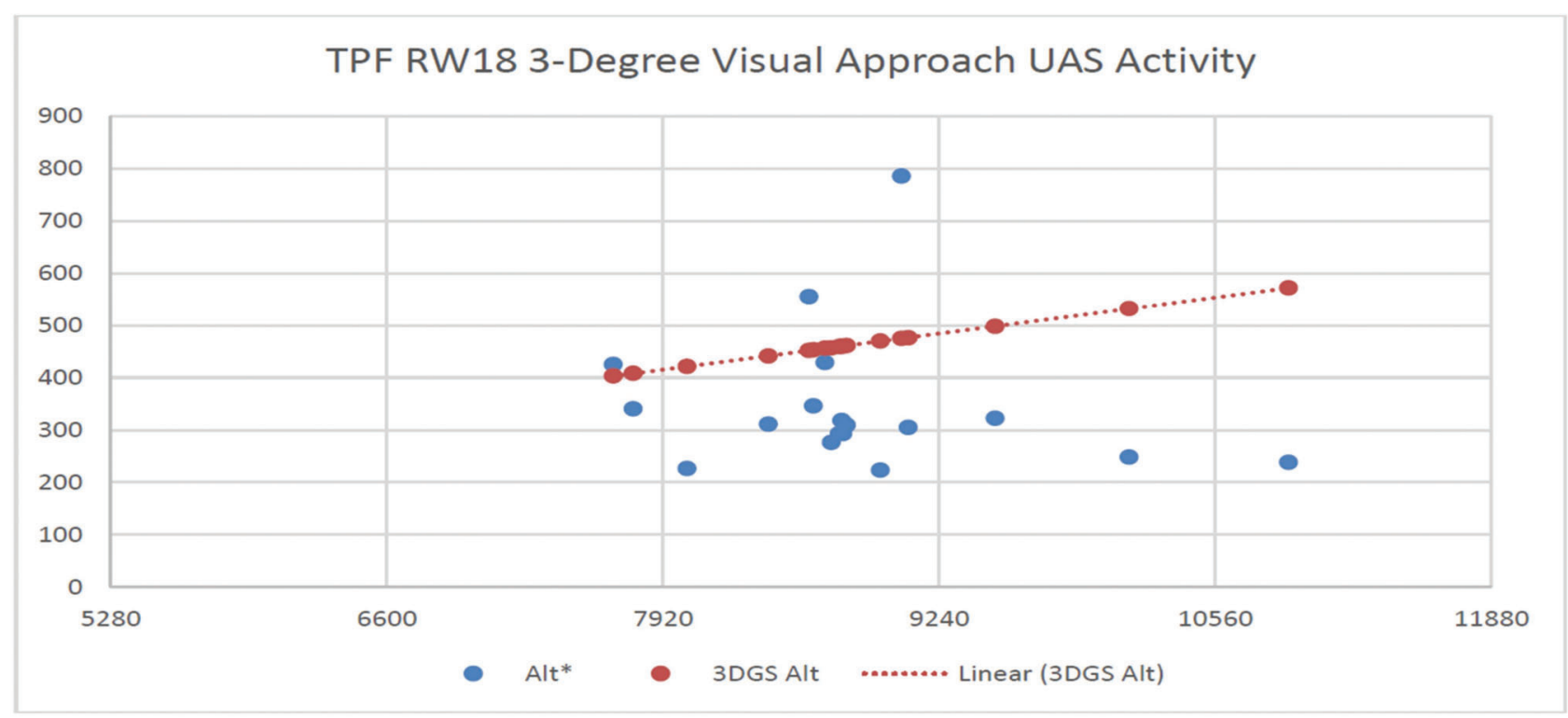

Figure 14. Peter O. Knight (TPF) airport $3^{\circ}$ visual approach profile with UAS activity plotted within $\pm 10^{\circ}$ lateral approach wedge. Displayed in lateral $0.25 \mathrm{SM}$ increments from 1.0 to $2.25 \mathrm{SM}$ lateral and $100 \mathrm{ft}$ vertical increments, charted in feet. Orange trend line represents $3^{\circ}$ visual glideslope, with blue plots indicating detected UAS activity. *UAS altitude adjusted based on TPF airport elevation to display in AGL.

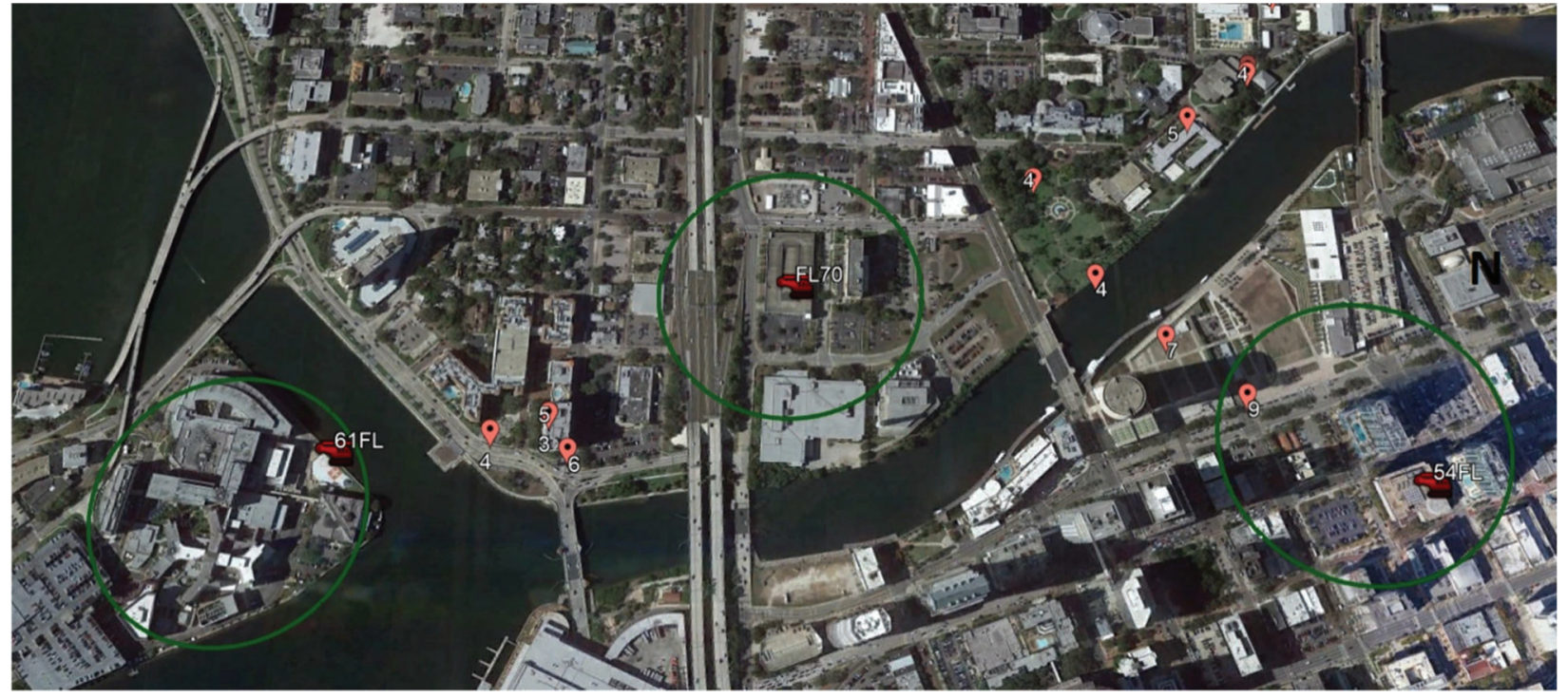

Figure 15. Heliport activity in downtown Tampa. AeroScope detections presented as pins with adjacent numerals representing altitude in hundreds of feet MSL. Heliports are represented with a red helicopter symbol, overlaid on helipad location. Green circles represent DJI warning zone geofencing, based on information derived from DJI (n.d.) on April 3, 2018.

notable that the center point for each of these geofenced areas does not necessarily correspond to the location of the helipad, which may allow unmanned aircraft and helicopter activity to come into proximity before UAS operators become aware of the potential hazard.

\section{Geofencing}

Based on the collected data, no flights were detected within Restricted Zones and two flights were detected in Authorization Zones, which represents $0.7 \%$ of the overall dataset $(N=258)$. Of the detected dataset, exactly $50.0 \%$ $(n=129)$ of detections occurred within Enhanced Warning Zones (11 overlapped between the TPA and TPF Enhanced Warning Zones but were only counted once). Nearly $88.0 \%$ of all detections $(n=227)$ occurred inside of one or more Warning Zones.

These findings indicate that while only $0.7 \%$ of UAS operators actively overrode geofence protections, at least $50.0 \%(n=129)$ of operators acknowledged warning messages but elected to continue flying in spite of area hazards. An overview of detected sUAS flights overlaid against DJI Restricted Zones is presented in Figure 16. 


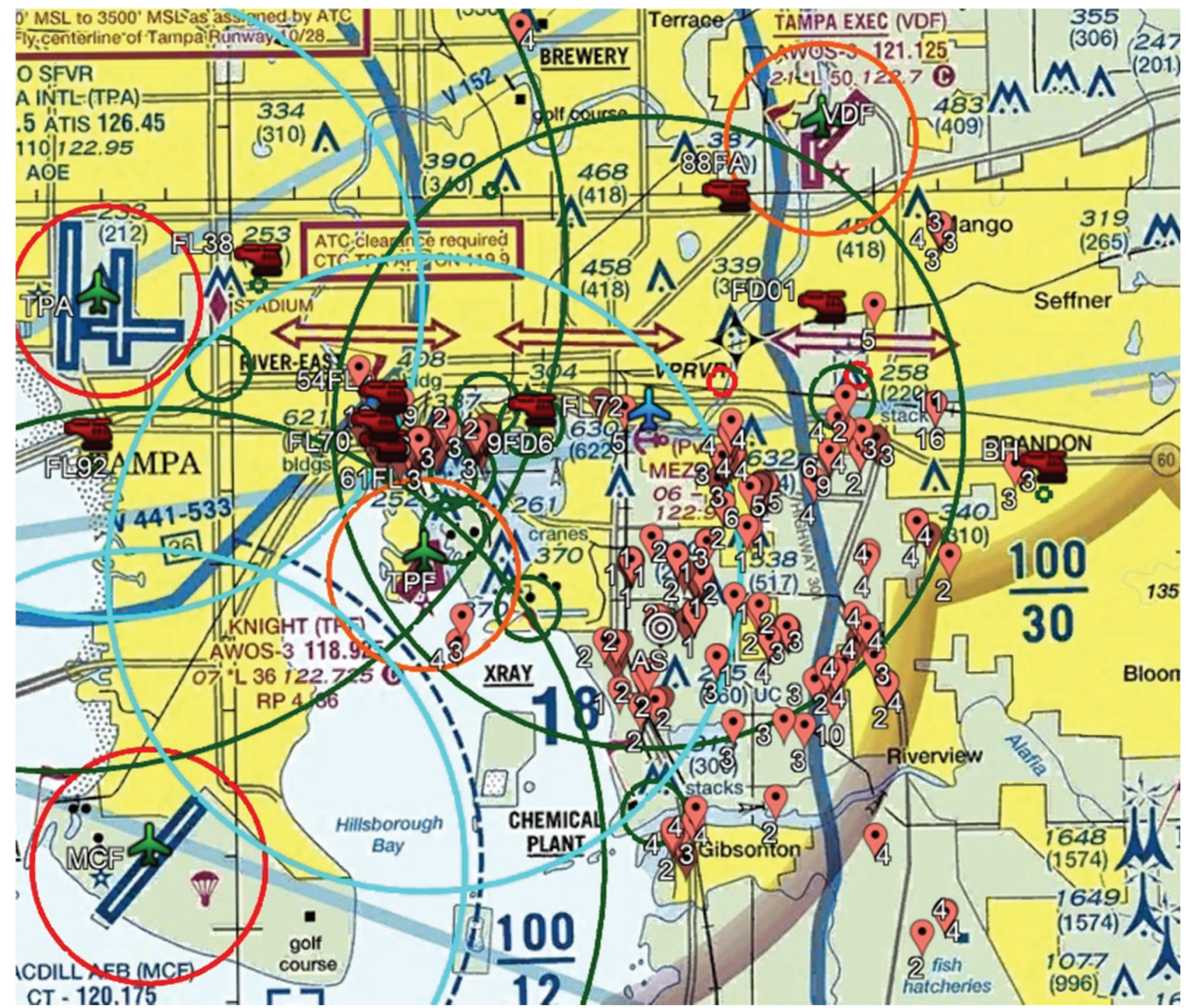

Figure 16. AeroScope detection data overlaid on Tampa Terminal Area Chart with DJI geofencing Restricted, Authorization, Enhanced Warning, and Warning Zones. Restricted Zones appear in red, Authorization Zones in orange, Enhanced Warning Zones in cyan, and Warning Zones in green. Geofencing data derived from DJI (n.d.) on April 3, 2018.

\section{Conclusions}

\section{UAS Flight Locations}

Data suggested that operators favored conducting flights in proximity to single-family homes and commercial or industrial locations. It is not an unreasonable assertion to suggest that operators are flying in direct proximity to their own homes. Similarly, operators are also conducting flights from commercial or industrial locations, usually from parking lots or other open areas. Parks did not seem to be as popular a flight location as researchers originally anticipated, with only $4 \%(n=11)$ of detections originating in those areas. Perhaps the most unexpected finding was the $8 \%(n=21)$ of flights carried out over public roadways.

\section{UAS Operator Behavior}

The collected data allude to several UAS operator characteristics:

\section{UAS operations altitude}

At least $18.2 \%(n=47)$ of flights were conducted above $400 \mathrm{ft}$ AGL. This finding indicates that many operators are ignorant of or willfully non-compliant with either $14 \mathrm{CFR}$ 107.51(b) regulations or AC 91-57A(C1) Sec 6(e) guidance, which limits UAS flight altitude to less than $400 \mathrm{ft}$ AGL. The detection of $11.6 \%(n=30)$ of UAS flights above $500 \mathrm{ft}$ AGL is worrisome, as such operations are likely to cause interference with manned operations-particularly in congested airspace. 
UAS operations date/time

Most midair collisions between manned aircraft occurred on warm weekends, during daylight hours and under visual meteorological conditions (FAA, n.d.c; Morris, 2005). Fortyseven percent of UAS detections occurred on Saturday or Sunday under visual meteorological conditions. While not definitive, the preliminary data suggest the risk of collisions between manned and unmanned aircraft may also be higher on fair-weather weekend days.

Data showed that UAS operators are conducting flights at nearly all hours of the day-in many cases breaking civil twilight limitations. The data suggest the majority of UAS flights tend to favor times between $3: 00 \mathrm{pm}$ and 9:00pm, with operations peaking between 7:00pm and 8:00pm.

\section{UAS operations duration}

The collected data suggested that operators generally flew for durations between 1 and $3 \mathrm{~min}$, with $64 \%$ of flights lasting $1 \mathrm{~min}$ or less. This is surprisingly short, considering that even the least capable detected UAS had an endurance of $16 \mathrm{~min}$. It is possible this finding could be in error, if several sUAS platforms moved outside of the AeroScope's electronic line of sight before the conclusion of their flights.

\section{Aeronautical Impact}

For the purpose of this study, potential regulatory violations were evaluated within the context of $14 \mathrm{CFR}$ 107 , since these regulatory provisions incorporate a riskbased approach to operational limitations.

Strong evidence suggests that many detected UAS operations were in violation of one or more provisions of 14 CFR 107, or otherwise conducted flights in a manner that presented a potential hazard to manned flight operations. At least $16.3 \%$ of flights $(n=42)$ appeared to violate daylight operation limitations prescribed in 14 CFR 107.29, by conducting flights during nighttime hours. Similarly, $18.2 \%$ of flights $(n=47)$ were flown in excess of the $400 \mathrm{ft}$ altitude limitation prescribed for sUAS under 14 CFR 107.51. Four UAS operations were found to have penetrated either the Tampa International Airport Class B Surface Area or Shelf, violating 14 CFR 107.41 provisions. Three of the four flights in Class B airspace far exceeded 1,000 ft AGL. Based on the assessed factors, the authors conclude that in the short, 19day sampling there could have been as many as 93 potential violations of $14 \mathrm{CFR} 107$. The authors reiterate that this summation of potential violations may include authorized activities that comply with Part 107 operational waivers, Part 333 exemptions/Certificates of Authorization, or 14 CFR 101 provisions. Nevertheless, the quantity of potential violations highlights an elevated risk of interference with manned aircraft operations.

The findings indicate a strong likelihood of potential interference with manned aircraft operations. UAS penetration into the Tampa International Class B Surface Area and surrounding shelf presented a distinct hazard to aircraft inbound, outbound, and transitioning through this densely trafficked environment. Moreover, significant UAS activity along the northern shoreline of Harbour Island induced potentially serious hazards to aircraft inbound to the Peter O. Knight airfield via the Runway 18 visual approach. Finally, the quantity, proximity, and altitude of UAS operations near downtown Tampa heliports are also problematic, indicating a clear collision hazard for lowaltitude rotorcraft operations.

\section{Geofencing}

The data suggested that DJI's Restricted Zones and Authorization Zones offered reasonable protection against intrusion with no penetrations of Restricted Zones and only two intrusions into Authorization Zones.

Conversely, the data suggested that at least $50.0 \%$ of detected flight operators acknowledged Enhanced Warning Zone messages but elected to continue their UAS flight. Similarly, $88.0 \%$ of operators elected to continue UAS flight into Warning Zones despite user interface warnings alerting them to local aeronautical hazards. The authors believe this finding highlights a deficiency in the aeronautical decision-making of detected sUAS operators. Moreover, this operator behavior suggests that geofencing protections are only effective if they impose some level of restriction upon the flight.

\section{Recommendations}

\section{Align Operational Rules}

The authors assert the large numbers of potential violations assessed under 14 CFR 107 rules are indicative of growing, systemic risks in the National Airspace System (NAS) posed by unmanned aircraft operations. Based on the high proportion of hobbyist registrations in the sample area, the authors suspect that the majority of detected sUAS operations represent hobbyist activity or flights not otherwise carried out under 14 CFR 107 provisions.

During the study, it was not possible to definitively distinguish between flights carried out under 14 CFR 107 rules versus flights carried out under 14 CFR 101 provisions. According to the FAA, the establishment of 14 CFR 107 "addresses [the provisions]...to maintain the safety of the NAS and ensure that small UAS do not pose a threat to national security" (FAA, n.d.b, p. 10). The FAA's risk-based approach to establishing specific operational restrictions under Part 107 is not replicated to the same extent under 14 CFR 101. With the exception of UAS weight, right of way, and aerodrome proximity rules, the FAA defers authority to establish operational limitations on model aircraft operators based on safety guidelines of nationwide community-based organizations. 
Even if sUAS operations were compliant with Part 101 rules, a notable percentage of the study's detected flights presented a significant risk to manned flight operations. The authors suggest that as currently written and implemented, the provisions of 14 CFR 101 do not adequately ensure safety for manned aircraft operations conducted in the NAS.

For these reasons, the authors recommend Congress consider revocation of the preamble contained in Section 336(a) of the FAA Modernization \& Reform Act of 2012, which would allow the FAA to codify and impose reasonable operational limitations on hobbyist and model aircraft activity to protect the safety of the NAS. Indeed, this recommendation is a moderated solution when compared to the legislative agenda of other advocacy groups. Both the Commercial Drone Alliance and the Air Line Pilots Association have called for wholesale revocation of the entirety of Section 336 (Air Line Pilots Association, 2018; Commercial Drone Alliance, 2018). Even the Academy of Model Aeronautics (2018) acknowledges the limitations associated with Section 336 provisions, stating that "some tweaks to Section 336 may be needed to clarify who the provision does and does not cover" (p. 1).

Succinctly, the authors ascertain the existing provisions of 14 CFR 101 do not provide adequate protection to manned aircraft operations within the NAS. The sample dataset indicates serious potential risks exist for manned aircraft, based on flights likely carried out by sUAS operators under 14 CFR 101 rules. In the absence of further geofencing, regulation, or other safety provisions, it is highly likely that sUAS operations will continue to represent the proverbial "Wild West" of aviation. As sUAS operations continue to proliferate into the NAS, the spillover of non-compliant sUAS flights into airspace traditionally occupied by manned aircraft will likely exacerbate collision risks unless immediate mitigation efforts are taken.

\section{Limitations}

This study had several identifiable limitations. Unfortunately, the AeroScope was only able to detect DJI sUAS platforms within the electronic line of sight of the detection device. Skylogic Research (2017) estimates that DJI platforms comprise approximately $72 \%$ of the small UAS market. In the event a detected UAS moved outside of the electronic line of sight of the AeroScope, the device may have created a separate record of the flight, possibly skewing detection data. The authors did not evaluate or adjust detection data based on these conditions. Additionally, the AeroScope is not yet configured to detect all models of DJI platforms. For example, the DJI Matrice 100 displays as an "unknown" platform type.

Several UAS detections appeared to be violations of established UAS regulations contained in 14 CFR 107 or 14 CFR 101(E). While such prima facie detections may appear to be violations, it is possible that operators exercised authority under an approved Section 333 exemption with accompanying Certificate of Waiver or Authorization, or via operational waivers described in 14 CFR 107(D). This study did not assess waivers or other methods of UAS regulatory compliance.

It should be noted that UAS operator behavior in the sample location may not necessarily be representative of operator behavior in other locations. Moreover, the authors did not assess how UAS operator behavior changed based on seasonal weather or other temporal factors.

\section{Future Research}

The authors intend to expand their assessment of unmanned aircraft activity to additional airfields to further refine results. Future research efforts will focus on collecting data in proximity to airports in Class C, D, and Surface Class E airspace.

\section{Acknowledgments}

The authors appreciate the participation of Mr. Ryan English and the rest of the FLYMOTION team, whose valuable contributions led to the success of this research project.

\section{References}

Academy of Model Aeronautics. (2018, April 5). AMA response to Commercial Drone Alliance [Web log post]. Retrieved from http:// amablog.modelaircraft.org/amagov/2018/04/05/ama-response-tocommercial-drone-alliance/

Air Line Pilots Association. (2018). Advocacy: Safe integration of unmanned aircraft systems [Web log post]. Retrieved from http:// www.alpa.org/advocacy/unmanned-aircraft-systems

Commercial Drone Alliance. (2018, June 14). Commercial Drone Alliance calls for Congress to repeal Section 336 of the FAA Modernization and Reform Act of 2012 [press release]. Retrieved from https://www. commercialdronealliance.org/newsarchive/cda-calls-for-congress-torepeal-section-336-of-the-modernization-reformation-act-of-2012

DJI. (2017a, October 12). DJI unveils technology to identify and track airborne drones [Web log post]. Retrieved from https://www.dji.com/ newsroom/news/dji-unveils-technology-to-identify-and-track-airbornedrones

DJI. (2017b). Inspire 2 user manual V1.4 [PDF file]. Retrieved from https://dl.djicdn.com/downloads/inspire_2/20171013/INSPIRE_2_ User_Manual_EN.pdf

DJI. (n.d.). Fly safe: GEO zone map [Web page and interactive map]. Retrieved from https://www.dji.com/flysafe/geo-map

FAA Modernization \& Reform Act of 2012, Pub. L. No. 112-95, §336a, 126 Stat. 11 (2012).

Federal Aviation Administration. (n.d.a). FAA aviation weather cameras: Sunrise, sunset \& twilight calculator [online calculator]. Retrieved from https://avcams.faa.gov/sunrise_sunset.php

Federal Aviation Administration. (n.d.b). FAA sUAS Part 107: The small UAS rule. Retrieved from https://www.faa.gov/uas/media/RIN_2120AJ60_Clean_Signed.pdf

Federal Aviation Administration. (n.d.c). How to avoid a mid air collision: P-8740-51 [Web page]. Retrieved from https://www.faasafety.gov/ gslac/alc/libview_normal.aspx $?$ id $=6851$ 
Federal Aviation Administration. (2016a, February 18). FAA, DHS CACI, UMD perform UAS detection work [Web page]. Retrieved from https://www.faa.gov/news/updates/?newsId =84810

Federal Aviation Administration. (2016b, July 1). FAA releases drone registration location data [database]. Retrieved from https://www.faa. gov/news/updates/?newsId $=85548$

Federal Aviation Administration. (2016c, July 1). UAS detection initiative [press release]. Retrieved from https://www.faa.gov/news/updates/?newsid=85532

Federal Aviation Administration. (2018). FAA aerospace forecast report: Fiscal years 2018-2038 (report no. TC18-0004). Washington, DC: Federal Aviation Administration. Retrieved from https://www.faa.gov/ data_research/aviation/aerospace_forecasts/media/FY2018-38_FAA Aerospace_Forecast.pdf

Federal Aviation Administration. (2019, February 15). UAS sightings report [Web page]. Retrieved from https://www.faa.gov/uas/resources/ public_records/uas_sightings_report/

Gettinger, D., \& Michel, A. H. (2015). Drone sightings and close encounters: An analysis. Annandale-on-Hudson, NY: Bard College Center for the Study of the Drone. Retrieved from http://dronecenter. bard.edu/drone-sightings-and-close-encounters/

Gettinger, D., \& Michel, A. (2017). Drone registrations: A preliminary analysis. Annandale-on-Hudson, NY: Bard College Center for the
Study of the Drone. Retrieved from http://dronecenter.bard.edu/files/ 2017/11/Drone-Registrations-Web-.pdf

Morris, C. C. (2005). Midair collisions: Limitations of the see-and-avoid concept in civil aviation. Aviation, Space, \& Environmental Medicine, 76(4), 357-365. Retrieved from https://www.researchgate.net/ publication/7907700_Midair_collisions_Limitations_of_the_see-andavoid_concept_in_civil_aviation

Sharma, R. S. (2016). Investigation into unmanned aircraft system incidents in the National Airspace System. International Journal of Aviation, Aeronautics, and Aerospace, 3(4), 1-57. https://doi.org/10. 15394/ijaaa.2016.1146

Skylogic Research. (2017). 2017 drone market sector prospectus: Opportunities and challenges in key market segments. Redwood City, CA: Skylogic Research. Retrieved from http://droneanalyst.com/ wp-content/uploads/2017/09/Skylogic-Research-2017-Drone-MarketSector-Report-PROSPECTUS.pdf

Weather Underground. (2018). Tampa International Airport Station [data set]. Retrieved from https://www.wunderground.com/history/airport/ KTPF/2018/4/24/DailyHistory.html?req_city $=$ KTPF\&req_state $=$ FL\& req_statename $=$ Florida\&reqdb.zip $=33606 \&$ reqdb. magic $=4 \&$ reqdb. $\mathrm{wmo}=99999$ 